\title{
Carmen Vicaría: presencia femenina en el desarrollo de la pedagogía musical en Colombia
}

\author{
Carmen Vicaría: Female Presence in the Development of \\ Musical Pedagogy in Colombia
}

Ana Sharon Fierro Henao

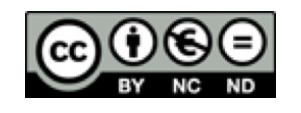

Esta obra está bajo una licencia Creative Commons Reconocimiento-No comercial-Sin Obra Derivada 
Dossier

\title{
Carmen Vicaría: presencia femenina en el desarrollo de la pedagogía musical en Colombia
}

\author{
Carmen Vicaría: Female Presence in the Development of \\ Musical Pedagogy in Colombia
}

\author{
Ana Sharon Fierro Henao ${ }^{1}$ \\ Caja de Compensación Familiar (CAFAM) \\ Colombia
}

Recibido: 30 de marzo de 2019 Aprobado: 24 de julio de 2019

\begin{abstract}
Resumen
En la historia de la pedagogía musical en Latinoamérica, detallamos elementos que son compatibles, de tal manera que en este caso directo, se manifiesta el papel de las mujeres como formadoras y docentes que prolongaron el conocimiento musical enseñando en sus casas o a domicilio. Esta línea común que se puede evidenciar en países como Argentina o Chile, también tuvo lugar en Colombia, donde muchas mujeres realizaron labores de enseñanza musical, un ejemplo de ello es Carmen Vicaría Pinzón, formadora de la región del Valle del Cauca, quien creó la academia de estudios musicales Carmen Vicaría desde 1919 hasta 1975, en la cual se generaron diversas pautas educativas que enriquecieron las capacidades de los niños y niñas del municipio de Guadalajara de Buga, dinamizando las actividades de dicha ciudad y promoviendo espacios de cultura y apreciación musical.
\end{abstract}

Palabras clave: música; pedagogía; mujeres; educación; piano

1 Docente de piano en Caja de Compensación Familiar (CAFAM), Colombia. Licenciada en Música por la Universidad del Valle, Colombia. Correo electrónico: ana.fierro@correounivalle.edu.com 
Carmen Vicaría: presencia femenina en el desarrollo de la pedagogía

Dossier musical en Colombia

\begin{abstract}
In the history of music pedagogy in Latin America, we detail elements that are compatible, in such a way that in this direct case, the role of women as educators and teachers who prolonged the musical knowledge teaching at home or at home is manifested. This common line that can be evidenced in countries such as Argentina or Chile, also took place in Colombia, where many women performed musical teaching, an example of this is Carmen Vicaría Pinzón, trainer from the Valle del Cauca region who created the academy of musical studies Carmen Vicaría from 1919 to 1975, generating various educational guidelines that enriched the capacities of children in the municipality of Guadalajara de Buga, boosting the activities of that city and promoting spaces of culture and musical appreciation.
\end{abstract}

Keywords: music; pedagogy; women; education; piano 
Esta investigación pretende visibilizar los procesos pedagógicos realizados por Carmen Vicaria Pinzón, quien fue una pianista de la capital colombiana, Bogotá, y desarrolló un centro de estudios musicales en la región del Valle del Cauca a comienzos del siglo XX. Como punto de partida, la investigación plantea identificar las herramientas pedagógicas que llevaron a Carmen a conformar uno de los primeros centros de educación musical formal en la recién configurada región del Valle del Cauca en Colombia, con lo cual dejó un legado de pianistas y espacios de interacción cultural y contribuyó al reconocimiento de la historia de tipo local y la reivindicación de la mujer como protagonista de los procesos musicales realizados en Colombia y Latinoamérica.

La historia de Carmen no es ajena a los procesos realizados en ese mismo contexto temporal en las demás ciudades de Latinoamérica, puesto que ella representaba un papel determinante respecto a la enseñanza musical. En Latinoamérica, la historia de la música puede arrojar rasgos de participación de la mujer en los espacios de educación musical, un panorama en el que se precisa la enseñanza de la música y las prácticas pedagógicas, vislumbrando un perfil de docente. Afirma Bracamontes (2011):

Algunas de ellas, avaladas por títulos docentes, desempeñan sus tareas en establecimientos educativos, ya sean oficiales o privados. Otras se dedican a la enseñanza en academias y conservatorios como profesoras de música, labores, idiomas, declamación, canto, dactilografía y baile infantil, así como también en institutos de formación para mujeres. Finalmente, debe mencionarse a quienes trabajan en forma independiente, en sus propios domicilios o como institutrices en casas de familia (p. 107).

En este sentido, se puede comprender la vinculación de las mujeres en los procesos de enseñanza como sujeto idóneo para ejercer una profesión y un papel en la sociedad. En la música no fue la excepción, un punto de referencia es la evidente participación de las mujeres como docentes de piano a domicilio o en sus propias residencias. Según Ruiz (2016), "como ya se señaló, las cuatro Profesoras fundadoras eran pianistas. Al crearse el Conservatorio Gladys Ruiz e Irene Timacheff ocuparon las cátedras de piano en tanto que Perla Baccari y Esther Amblard tomaron a su cargo las de Teoría y solfeo" (p. 8). Este entorno ilustrativo de los procesos desempeñados por mujeres en Latinoamérica en cuanto a la música, nos plantean una perspectiva, la mujer hizo parte de la prolongación del conocimiento musical. Becker (2011) afirma que:

El rol femenino en el ámbito de salón decimonónico de las elites intelectuales y las reuniones sociales en torno a la cultura y el arte, estaba estrechamente relacionado con sus capacidades musicales. Para ello era indispensable que ellas supieran "entretener" al público tocando para ellos al piano, la guitarra, canto, arpa, y algún otro instrumento, por supuesto siempre en vigilancia de la presencia masculina (p. 4). 
Carmen Vicaría: presencia femenina en el desarrollo de la pedagogía

Dossier musical en Colombia

Asimismo, en otros países de Latinoamérica como Venezuela, los procesos de conservatorios fueron vitales para la formación de mujeres en el aprendizaje musical. Según Agostini (s.f.):

La influencia de artistas extranjeras, la creación de academias y escuelas especializadas en las bellas artes, el acceso a los libros y a la prensa, las clases particulares con eminentes pedagogos y la necesidad de hacer algo más que coser, bailar, leer y rezar, permitieron a las venezolanas penetrar en el mundo artístico de la escritura, poesía, la actuación y la música, entre otras (p. 12).

Por ello, la presente investigación busca contribuir y participar en la reconstrucción de la historia de la música, contada desde los avatares de las mujeres docentes, que significaron un aporte a la creación de centros de educación musical formal a través del piano como instrumento. Galindo (2012) dice: "la mujer en Colombia se relaciona con la práctica musical, con la llegada de los primeros pianos (como se cita en Bermúdez)" (p. 181). Es entonces que se trae a colación la figura de María del Carmen Vicaría Pinzón como una de las primeras formadoras de la región del Valle del Cauca en Colombia. Casas (2014) indica que "solo hacia finales de 1920 y con la llegada a Buga de la maestra Carmen Vicaría Pinzón, egresada del Conservatorio Nacional de Música la actividad pianística adquiere gran auge en Buga" (p. 102).

María del Carmen Vicaría nació en 1896 en Santa Fe de Bogotá, Colombia (Ena Victoria Escobar, 11 de agosto 2016, comunicación personal), la ciudad capital que por esos días reflejaba un fuerte gusto musical y el deseo de enaltecer su imagen y distinción con las prácticas musicales y para ello era indispensable que las señoritas de la elite interpretaran el piano. De acuerdo con Barriga (2002), "a simple vista parecería que los estudios musicales formales estaban dirigidos a las damas más distinguidas de la sociedad" (p. 17). Carmen desde su infancia, se acercó al piano y en sus años de juventud ingresó a la Academia Nacional de Música para formarse como profesional, debido a que existía una sección de señoritas. Casas (2012) Afirma que:

Inició su formación musical con la maestra Lucia Páez y posteriormente ingresó al conservatorio nacional (en ese entonces academia nacional de música), en la calle 19 con carrera 8 donde se formó bajo la dirección de Guillermo Uribe Holguín y obtuvo el diploma de estudios musicales (p. 262).

Por tanto, las relaciones sociales y académicas que antecedían dichas prácticas profesionales en las mujeres, en las que se incluye Carmen, se reconfiguraron, hasta el punto de aperturar un nuevo espacio de desarrollo personal femenino. En 1880, el cultivo de la música constituyó un adorno más y un placer doméstico para la mujer bogotana de la élite. Pero a partir de 1887, con la apertura de la sección de señoritas en la Academia Nacional de Música (fundada en 1882) se abrió una alternativa de trabajo para la mujer (Barriga, 2004, p. 12).

ESCENA. Revista de las artes, 2020, Vol. 79, Núm. 2 (enero-junio), pp. 174-188 
Después de dicha Formación y de casarse con Luis Escobar Cruz, abogado proveniente del suroccidente colombiano (Ena Victoria Escobar, 11 de agosto 2016, comunicación personal), Carmen viajó al Valle del Cauca en 1917 y recorrió ciudades como Tulúa y Cartago, pero no encontró allí la interacción musical que buscaba, como si lo halló en Guadalajara de Buga por ser un municipio de alta distinción social debido a que las principales familias eran en su mayoría descendientes directos de españoles en la época de la colonia. De acuerdo con Tascón:

Los españoles tenían necesidad de ocupar esta región, tanto por ser una de las más ricas e importantes, como para tener una vía de comunicación por la banda derecha del río Cauca, con Cartago y demás poblaciones del norte de la Gobernación (Tascón, 1938, p. 33).

Por esta razón, la ciudad de Buga fue la indicada para relacionarse con el arte y los procesos educativos que proponía Carmen. De esta manera Guadalajara de Buga fue la primera ciudad en la región en contar con un espacio académico para la música. Casas (2014) expone que:

Es necesario tener en cuenta que en la región no existió un conservatorio hasta 1933, cuando se fundó el conservatorio de occidente. Precedido por la escuela de Carmen Vicaría Pinzón que tenía la única escuela de estudios musicales en Buga, a finales de la segunda década del Siglo XX (p. 32).

Es el año de 1919 en el cual se crea su academia de estudios musicales Carmen Vicaría, donde por varias décadas impartió la educación musical formal. "Imagínese usted que mi mamá primero se fue para Tulúa y Cartago, después llegó a Buga y ahí sí creo la academia con seis pianos en la casa de la carrera 15" (Ena Victoria Escobar, 11 de agosto de 2016, comunicación personal).

El centro de estudios musicales de Carmen era el espacio indicado para que los bugueños de las elites intelectuales, de las familias distinguidas y las familias judías pudieran ver representado su gusto musical y su similitud con la cultura europea. Buga recibía constantemente la visita de óperas, conjuntos instrumentales, entre otras actividades artísticas, "Buga siempre tuvo compañías de teatro muy famosas que venían en los años cuarenta, de zarzuela y de todas esas cosas" (Lucia Mórela, comunicación personal, 16 de enero de 2018).

Diariamente niñas y niños acudían a la casa de Carmen que estaba rodeada de pájaros y notas musicales. En los pianos de su casa se sentaban a recibir lección por lección, atendiendo las exigencias de su maestra, que recalcaba la importancia de la teoría musical, la práctica de las escalas, la técnica de la mano izquierda y la mano derecha minuciosamente (Miguel Ángel Cuadros, Carlos Montoya, comunicación personal). Todos 
estos parámetros establecidos por Carmen Vicaría estaban articulados a los métodos pianísticos como Czerny, Hannon, Stamaty, Brimhall y Schmoll. Métodos que ella misma traía de la casa musical Conti en Bogotá, de esta manera procuraba estar a la vanguardia de las tendencias musicales desarrolladas en la capital del país. "Mi mamá se iba a Bogotá a traer material para la academia, llegaba con esos métodos de Hannon, Czerny y Stamaty, era muy estricta con las escalas y las posturas" (Ena Victoria Escobar, 11 de agosto de 2016, comunicación personal).

Las estrategias pedagógicas propuestas por Carmen, estaban entrelazadas con los métodos mencionados anteriormente y dejaban en claro su vocación docente y su deseo por establecer verdaderas pautas educativas que propiciaran una mayor compresión en el estudiante a la hora de enfrentarse al universo musical, con todo lo que dicho accionar

Figura 1. Recorte de periódico

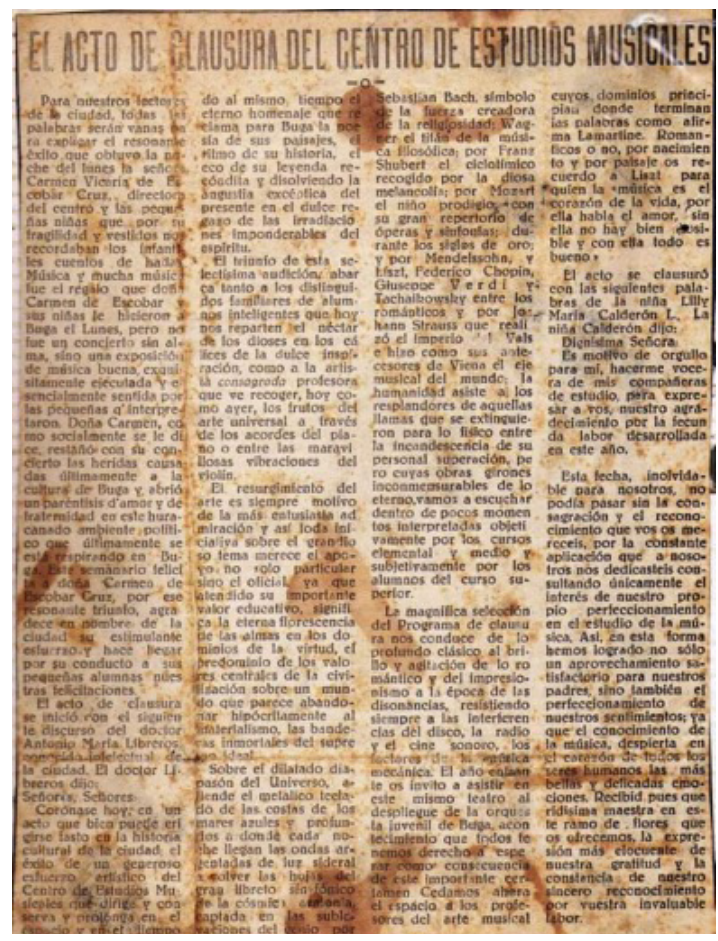

Fuente: documento recuperado del archivo personal de Ena Victoria Escobar. conlleva. Leer partitura, entender la teoría musical, posturas del cuerpo y las manos, técnica e interpretación, eran unos de los aspectos fundamentales en la formación que brindaba Vicaría. "La maestra Carmen tenía muy claro qué enseñarle a cada uno con sus libros de piano, muchas cosas de las que sé, son gracias a ella" (Gertrudis Kremer, 9 de octubre de 2017, comunicación personal)2.

Asimismo, la academia de Carmen contaba con una jerarquización de niveles, estaba el nivel elemental, que era el curso de los más pequeños en el cual se buscaba dejar muy claro los aspectos técnicos y establecer una disciplina con el instrumento. El nivel medio, en el que los estudiantes combinaban su técnica con la práctica de piezas sencillas en busca del desarrollo auditivo y motor.

En el nivel superior los estudiantes ya tenían una claridad en los aspectos técnicos así que los objetivos estaban dirigidos a una buena interpretación, con repertorio más avanzado que combinaban a Johan Sebastián Bach, con obras de Beethoven y Mozart. Como también el

${ }^{2}$ Gertrudis Kremer fue estudiante de Carmen Vicaría, actualmente, es pianista y docente de piano. 
repertorio a cuatro manos que les permitía tener conciencia del tiempo en un ensamble musical ${ }^{3}$.

En estos procesos las enseñanzas de Carmen Vicaría fueron indispensables, sus clases diarias conservaban la constancia y la disciplina necesaria para que cada uno de los estudiantes perfeccionara sus habilidades y pudieran tener un buen desempeño en las ceremonias de clausura que se realizaban anualmente como una muestra para los padres de familia y demás habitantes de la ciudad, conocedores de la música académica, intelectuales y políticos. "Viera usted como se llenaban las clausuras, iban los padres de familia y mucha 'gente de bien'”4 (Ena Victoria Escobar, 20 de noviembre de 2017, comunicación personal).

Figura 2. Los estudiantes de Carmen interpretando piezas a cuatro manos 1950

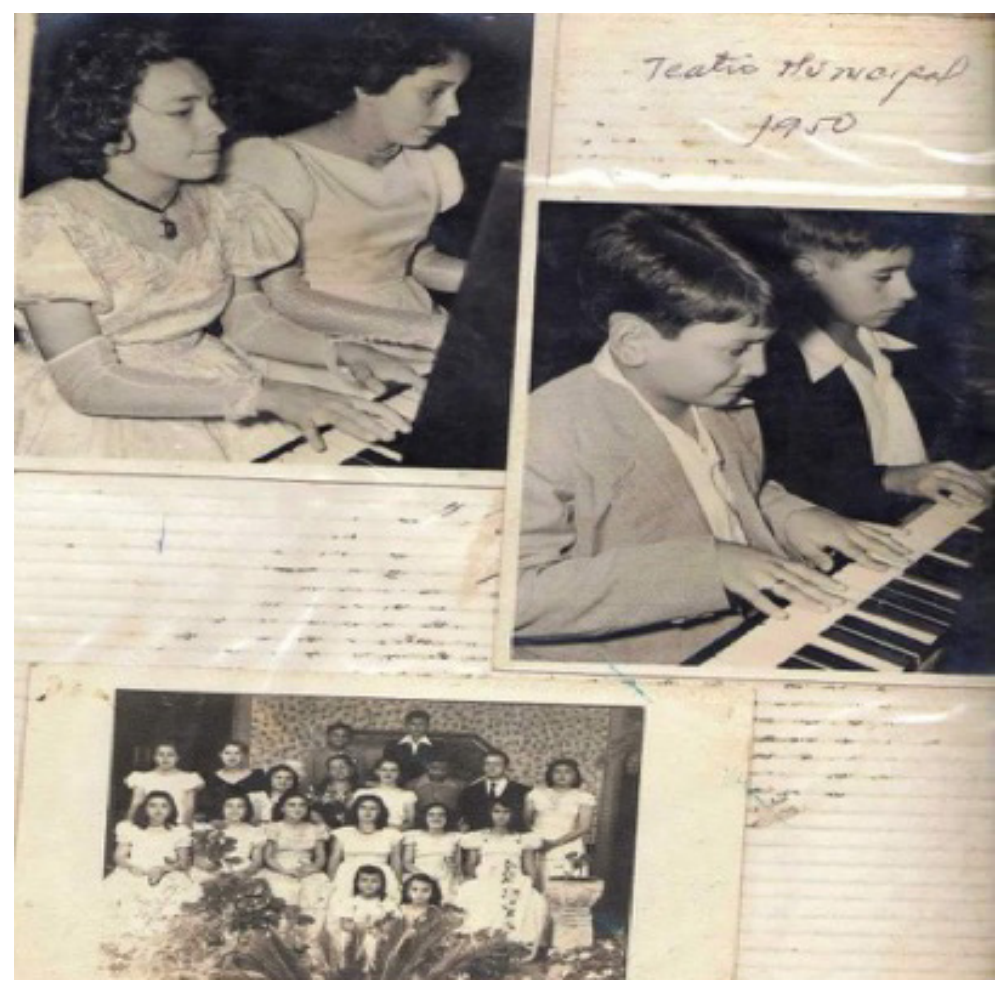

Fuente: fotos recuperadas del archivo personal de Ena Victoria Escobar Vicaría.

3 "Vamos a escuchar dentro de pocos momentos interpretadas objetivamente por los cursos elemental y medio y subjetivamente por los alumnos del curso superior"

${ }^{4}$ Según la Real Academia de la Lengua Española (RAE), "gente bien" significa: gente de posición social y económica elevada. 
Carmen Vicaría: presencia femenina en el desarrollo de la pedagogía

Dossier musical en Colombia

Figura 3. Clausura de 1955 en la academia de estudios musicales

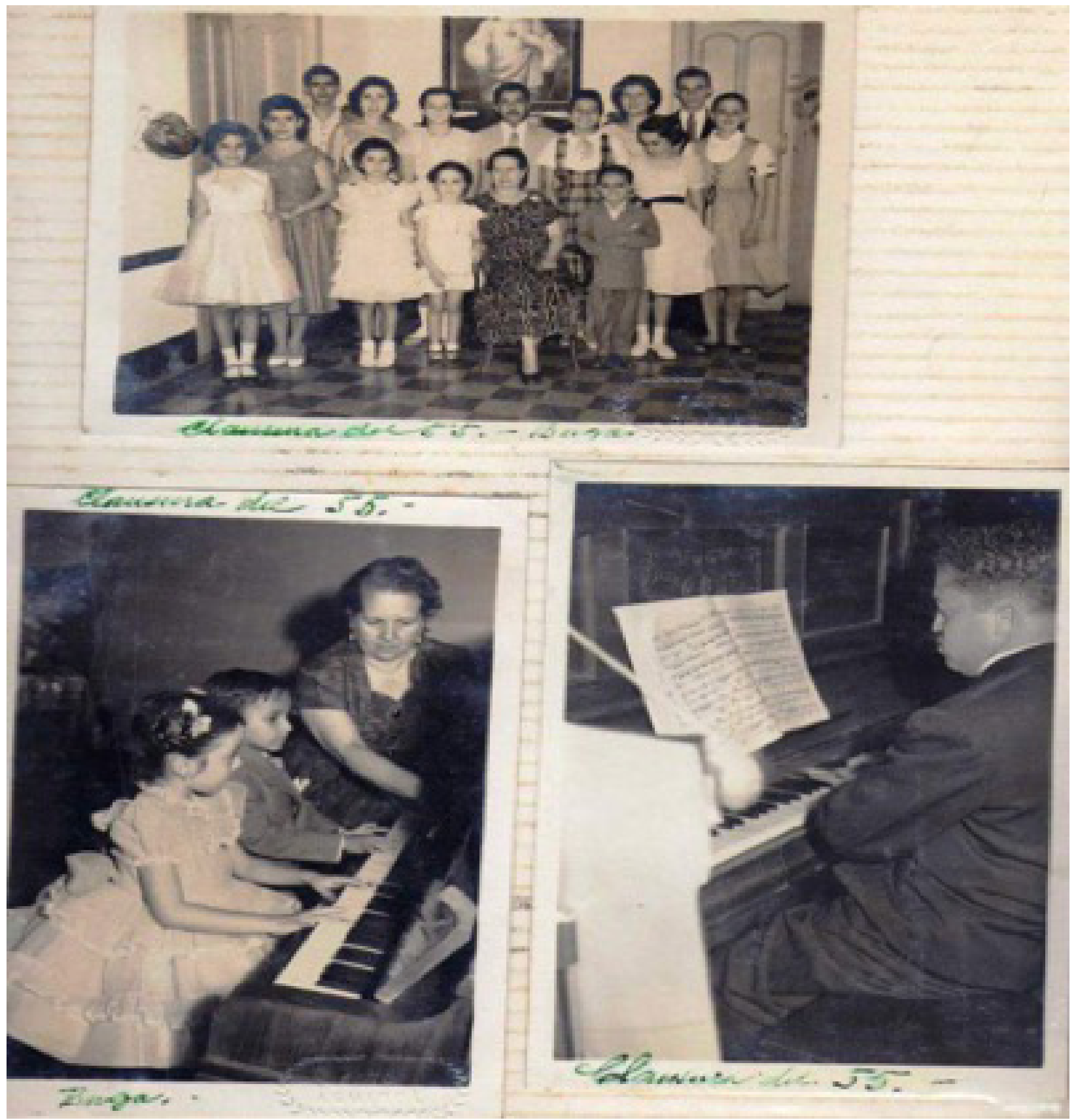

Fuente: fotos recuperadas del archivo personal de Ena Victoria Escobar Vicaría.

ESCENA. Revista de las artes, 2020, Vol. 79, Núm. 2 (enero-junio), pp. 174-188 
Figura 4. Ceremonia de Clausura de la academia de estudios musicales 1965 y 1966

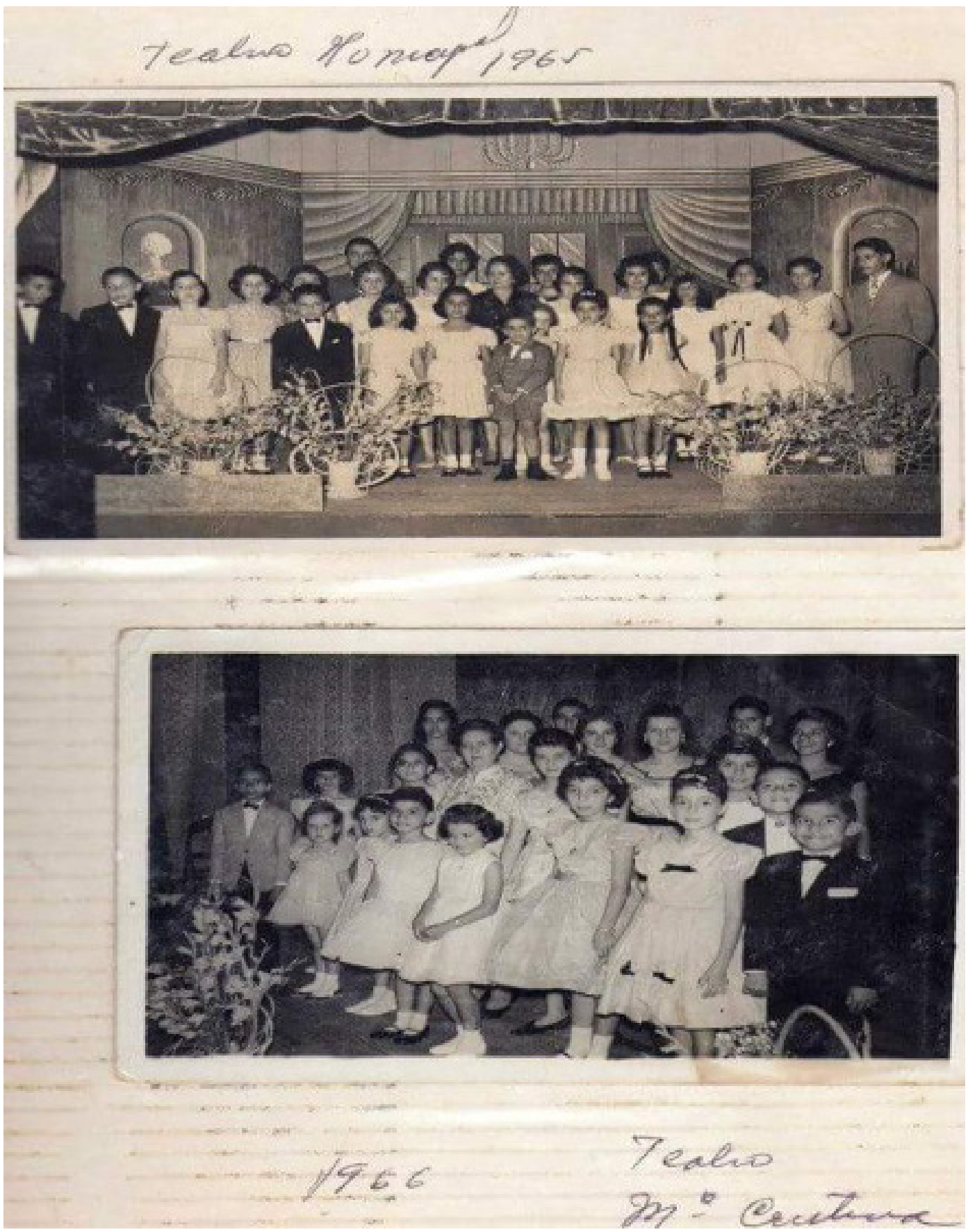

Fuente: fotos recuperadas del archivo personal de Ena Victoria Escobar Vicaría.

ESCENA. Revista de las artes, 2020, Vol. 79, Núm. 2 (enero-junio), pp. 174-188 
Carmen Vicaría: presencia femenina en el desarrollo de la pedagogía

Dossier musical en Colombia

Las ceremonias de clausura eran un importante evento cultural para la ciudad de Guadalajara de Buga que, recientemente, estaba dando muestras de progreso, con la instalación de la luz eléctrica, el ferrocarril del Pacífico, el acueducto y la ornamentación de las calles. De acuerdo con Cuevas (2016), "solo queda decir que, el acueducto de hierro se inauguró en 1912, el alcantarillado poco antes de 1913, la electricidad se instaló entre 1914-1916, y el adoquinamiento de las calles centrales se adelantó principalmente en las décadas 1910 y 1920" (p. 198). Estos cambios en Buga fueron clave para la modernización, la planificación de la ciudad y también reflejaban un estilo de ciudad que aceptaría la actividad musical y cultural que proponía Carmen. Expone Gutiérrez:

Ya para los años de 1929, Buga era una pequeña ciudad que solo tenía 272 manzanas, 19 calles, 19 carreras, 33.325 habitantes y un presupuesto de $\$ 25.611$ además de ello en menos de 10 años, Buga había logrado la llegada de la locomotora y el automóvil, también la energía eléctrica, todos los cuales trajeron importantes trasformaciones (citado en Morales, 2014, p. 10).

Cabe anotar que el Valle del Cauca era un naciente departamento en el que las ciudades de Cali y Buga se disputaban el protagonismo. Según Paredes:

Por decreto 340 de 16 de abril de 1910. Orgánico de la ley 65 de 1909 dictado por el general Reyes y su ministro de gobierno, Miguel Abadía Méndez, se dividió nuevamente el territorio nacional en trece (13) departamentos, uniendo los antiguos de Buga y Cali, para formar el actual departamento del Valle, con capital Cali, desde el 1 de Mayo de 1910 (citado en Gonzales, 2014, p. 5).

De igual forma, Buga ocupó el lugar de capital en el año de 1908. Morales (2014) afirma que: "para ese entonces el departamento de Buga estaba conformado por los municipios de Buga, Cerrito, Guacarí, San Pedro, Tuluá, Bugalagrande, San Vicente, Zarzal, Roldanillo, Bolívar, Huasanó, Toro, Yotoco, Unión, Cartago y Victoria” (p. 8). Además de la creación de la emisora Voces de Occidente, que empezaba a asumir bastante popularidad como nuevo medio de comunicación y que tendría relación directa con los procesos académicos de Carmen. De acuerdo con Durango (2015):

Ese sábado a las siete y treinta de la noche los Bugueños escucharon la programación inaugural de la emisora, durante la cual se presentó el tenor José Vicente Calero, la soprano Rosita Figueroa, el grupo musical de doña Carmen Vicaría y la orquesta de Efraín Orozco de Bogotá (p. 71)

Las clausuras de Carmen eran transmitidas en vivo por la radio Voces de Occidente, lo cual generaba una difusión de los procesos musicales que lideraba Vicaría y, de esta manera, se empezaba a educar al público bugueño en la escucha de la música académica. 
Figura 5. Transmisión radial

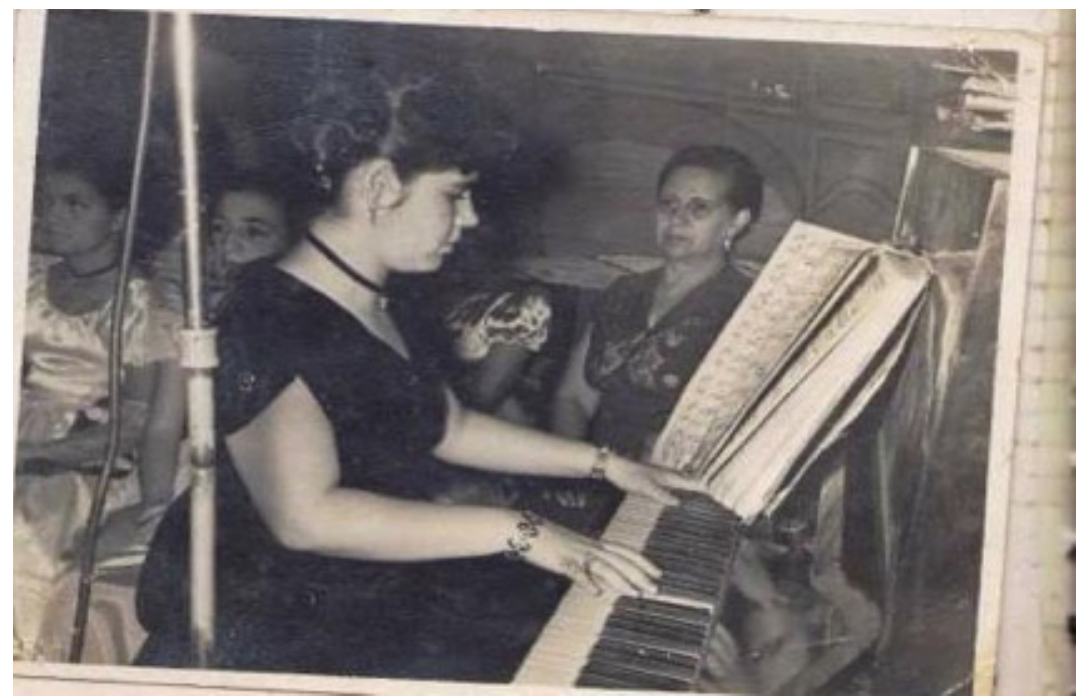

Fuente: foto recuperada del archivo personal de Ena Victoria Escobar Vicaría.
A la par de su labor pedagógica Carmen Vicaría dinamizo la actividad cultural de Guadalajara de Buga, con la conformación de coros y grupos de cámara que fueron protagonistas de los espacios públicos y privados de la ciudad, espacialmente en los eventos litúrgicos debido a que Buga era una ciudad sumamente religiosa. Abadía (2016) afirma: "la cotidianidad en Guadalajara de Buga estuvo impregnada de una importante sacralización de los espacios, las fiestas y las prácticas religiosas católicas las cuales giraban en torno preponderantemente a la imagen del señor de los milagros" (p. 147).

Es evidente que la presencia de Carmen Vicaría en la ciudad de Buga, marco un precedente respecto a la educación musical formal en la región del Valle del Cauca, siendo pionera en estructurar el aprendizaje musical con la conformación de su academia, en la cual se implementaron métodos pianísticos, de la mano de un fuerte rigor académico. Casas (2014):

Para el periodo de 1885-1930 Susana es un importante motor de la práctica musical pianística en Buga, al lado de la más reconocida pianista en el Valle del Cauca a partir de la década del 20 y durante casi treinta años en el municipio: Carmen Vicaría Pinzón (p. 50).

Además, Carmen fue un referente de la profesión musical al desempeñarse como docente, intérprete, directora de coros, directora
Figura 7. Carmen y su conjunto de cuerdas "Unión Musical"

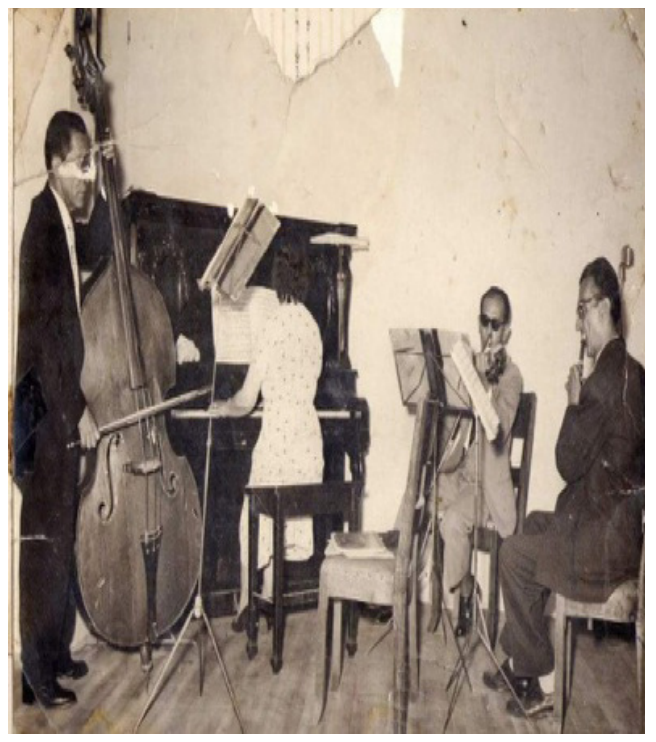

Fuente: foto recuperada del archivo personal de Ena Victoria Escobar Vicaría. 
Carmen Vicaría: presencia femenina en el desarrollo de la pedagogía

Dossier musical en Colombia

de conjuntos de cámara y como dinamizadora cultural del municipio e incluso Carmen fue pianista acompañante para las películas mudas que llegaban por esos días a la ciudad.

Figura 8. Orquesta y coro dirigidos por Carmen Vicaría Pinzón

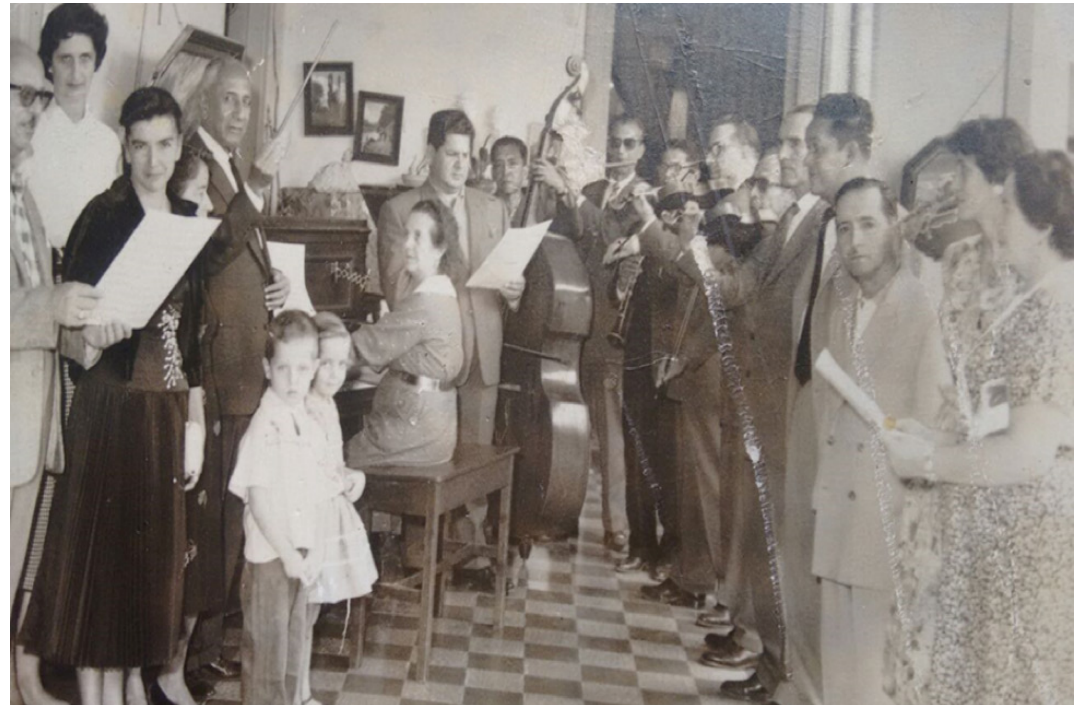

Fuente: foto recuperada del archivo personal de Ena Victoria Escobar Vicaría.

No era de mano muy grande, pero tenía el gran recurso muy desarrollado de tocar saltos de octavas muy precisos. Su pulsación era fuerte y sus dedos siempre sintiendo el teclado; en alguna conversación que tuvimos me contó que en la época del cine mudo ella toco en salas de teatro musicalizando estas. (Carlos Montoya, 23 de Junio 2017, comunicación personal) ${ }^{5}$.

María del Carmen tenía un perfil altamente profesional en el que diversificaba sus habilidades musicales y de liderazgo, inspirando así a muchas generaciones que decidieron continuar con su legado musical. Entre ellos se destacan Ruth Marulanda, Rodrigo Valencia, Carlos Montoya, Gertrudis Kremer y Cilia Arce quienes se han desempeñaron como músicos, productores, docentes y compositores en su trayectoria musical.

Finalmente la historia de Carmen Vicaría es una fiel imagen de los procesos que han sido llevados a cabo por mujeres y han representado un lugar determinante en la sociedad. Carmen desarrollo su academia musical por casi tres décadas estableciendo componentes directos para la educación musical formal, como el camino indicado para la apropiación de conocimientos musicales y la interpretación del piano. Entre 1919 y 1975 Carmen sostuvo una interacción con la comunidad bugueña, en la que impacto de manera positiva las actividades y visiones artísticas de los habitantes, al generar espacios de aprendizaje y apreciación musical. Además, estableció otras perspectivas respecto a la profesión musical, la elaboración de un pénsum académico en música, la creación de

${ }^{5}$ Compositor y productor musical, quien fue estudiante de Carmen desde 1970 a 1973.

ESCENA. Revista de las artes, 2020, Vol. 79, Núm. 2 (enero-junio), pp. 174-188 
colectivos en pro del arte y la cultura. Como también la visibilización de la mujer como líder de procesos de sensibilización y difusión musical.

Figura 9. Condecoración a Carmen Vicaría, el día del educador en el conservatorio de Cali

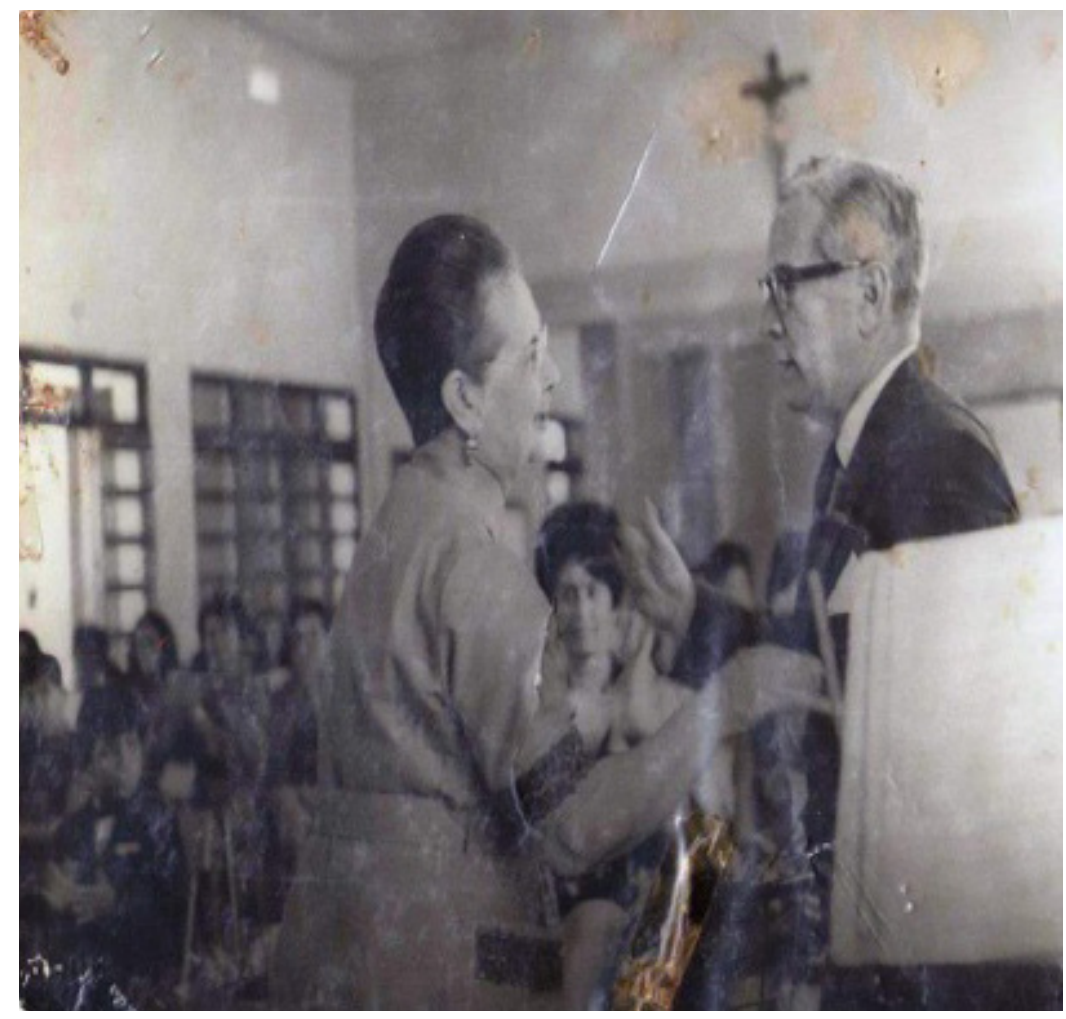

Fuente: foto recuperada del archivo personal de Ena Victoria Escobar Vicaría.

\section{Referencias}

Abadía, C. (2016) Érase una vez una ciudad devota: descripciones de las prácticas religiosas, católicas de Guadalajara de Buga (1910-1935). Guadalajara de Buga, Colombia. Programa Editorial de la Universidad del Valle.

Agostini, D. (s.f). Las mujeres en la música del siglo XIX venezolano. Recuperado de https://es.scribd.com/document/278300520/Las-Mujeres-en-La-Musica-Del-Siglo-XIX-Venezolano-Por-Desiree-Agostini

Barriga, M. (2002). La educación musical de la mujer en Bogotá de 1880 a 1920. Revista Historia De La Educación Latinoamericana, (4). Recuperado de https://revistas. uptc.edu.co/index.php/historia_educacion_latinamerican/article/view/147 
Carmen Vicaría: presencia femenina en el desarrollo de la pedagogía

Dossier

musical en Colombia

Barriga, M. (2004). La educación musical en Pamplona 1880-1920. El Artista, (1), 7-17. Recuperado de http://www.redalyc.org/pdf/874/87400205.pdf

Becker, G. (2011). Las mujeres en la música chilena: diálogos entrecruzados con el poder. Barcelona, España Transcultural de música, 15, 1-27. Trans. Revista Transcultural de Música, (15), 1-27.

Bracamontes, L. (2011) Mujeres, trabajo y educación a principios del siglo XX: las maestras en la prensa católica del sudoeste bonaerense argentino. Diálogos, Revista Electrónica de Historia, 12(1), febrero-agosto 2011. / pp. 101-127

Casas, M. (2012). En el silencio del piano: intérpretes y formadoras en las primeras décadas del siglo XX (un estudio de casos en Buga, Valle del Cauca). Bogotá: Pontificia Universidad Javeriana.

Casas, M. (2014). Álbum de partituras de Susana Cifuentes Salcedo (1883-1930), ecos de la historia Bugueña. Cali, Colombia: Colección Historia y Espacio.

Cuevas, H. (2016). Visiones y representaciones sobre la transformación urbana de Buga (Colombia), 1900-193. HiSTOReLo. Revista de Historia Regional y Local, 8(16), 193-227. DOl: https://doi.org/10.15446/historelo.v8n16.52183

Durango, E. (2015). Voces de occidente: Radiodifusora de Guadalajara de Buga entre 1941 y 1950 (tesis de pregrado). Universidad del Valle, sede Buga.

Galindo, H. (2012). Tradición y presencia femenina en la construcción musical de la región: mujeres en la música del Tolima. Bogotá, Colombia: Pontificia Universidad Javeriana.

González, D. (2014). Catalogación del tomo 121 del fondo cabildo de 1918-1921, depositado en el archivo de la academia de historia "Leonardo Tascon" de Guadalajara de Buga (tesis de pregrado). Universidad del Valle, sede Buga.

Morales, J. (2014). Las celebraciones religiosas católicas en la ciudad de Guadalajara de Buga. 1900-1930 (tesis pregrado). Universidad del Valle, sede Buga.

Real Academia Española. (s.f.). Diccionario de la lengua española. Recuperado de http://dle.rae.es/srv/fetch?id=J63pTV

Ruiz, G. (2016). La enseñanza del piano en la primera mitad del siglo XX en Villa María, Cba. Recuperado de http://bibliotecadigital.uca.edu.ar/greenstone/collect/Ponencias/tmp/ensenanza-piano-siglo-xx-ruiz.html

Táscon, T. (1938). Historia de la conquista de Buga (segunda edición). Bogotá: Editorial Minerva.

ESCENA. Revista de las artes, 2020, Vol. 79, Núm. 2 (enero-junio), pp. 174-188 